\title{
REDUÇÃO DO ESCOPO OU AMPLIAÇÃO DA PRÁTICA? AS PERSPECTIVAS DO MARKETING NA VISÃO DE SEUS ACADÊMICOS ${ }^{1}$
}

\author{
Natália Fontoura Englert ${ }^{2}$ \\ Ricardo Saraiva Frio ${ }^{3}$ \\ Carlos Sérgio Valdez Saldanha ${ }^{4}$ \\ Carlos Alberto Vargas Rossi ${ }^{5}$
}

http://dx.doi.org/10.1590/1413-2311.206.82108

\section{RESUMO}

Este artigo tem por objetivo explorar a visão de acadêmicos da área de Marketing sobre o escopo conceitual do Marketing. Através de uma pesquisa exploratória, foram realizadas entrevistas semiestruturadas com professores da disciplina. Tendo como intuito analisar a visão dos mesmos sobre questões que ainda hoje permeiam o debate acadêmico da área: o escopo do Marketing - e a necessidade ou não de sua revisão, seus limites de atuação, a dicotomia entre teoria e prática e, acima de tudo, a questão acerca da cientificidade ou não da disciplina. Pela visão dos seus acadêmicos, o artigo visa ampliar a discussão sobre como fortalecer a disciplina de Marketing, gerando insights que possibilitem avanços para o seu próprio corpo teórico. De maneira geral, foi possível observar que a visão predominante entre os acadêmicos pesquisados é de que o Marketing não precisa reduzir seu escopo teórico, mas sim aproximar os achados de suas pesquisas da prática, das questões reais do dia-a-dia da sociedade.

\footnotetext{
${ }^{1}$ Recebido em 19/04/2018, aceito para publicação em 21/06/2018.

${ }^{2}$ Universidade Federal do Rio Grande do Sul (Porto Alegre, RS, Brasil) - natalia.englert@gmail.com

${ }^{3}$ Universidade Federal do Rio Grande e UFRGS (Rio Grande e Porto Alegre, RS, Brasil) ricardo.frio@yahoo.com.br

${ }^{4}$ Universidade Federal do Rio Grande do Sul (Porto Alegre, RS, Brasil) - csaldanha@terra.com.br

${ }^{5}$ PPGA - Universidade Federal do Rio Grande do Sul (Porto Alegre, RS, Brasil) - cavrossi@terra.com.br
} 
Palavras-chave: Teoria de Marketing. Escopo de Marketing. Prática de Marketing.

\title{
REDUCING THE SCOPE OR EXPANDING THE PRACTICE? THE MARKETING PERSPECTIVE ACCORDING TO THEIR RESEARCHERS
}

\begin{abstract}
This article aims to study the understanding of academic Marketing researchers on the conceptual scope of Marketing. Through an exploratory research, semi-structured interviews with teachers of the discipline were carried out. With the aim of analyzing their view on issues that still permeate the academic debate in the area: the scope of Marketing - and the need for its revision, its limits, the dichotomy between theory and practice and, above all, the question of whether the discipline is scientific or not. From the point-of-view of its academics, the article aims to broaden the discussion of how to strengthen the discipline of Marketing, generating insights that enable breakthroughs for its own theoretical body. Overall, it was observed that the prevailing understanding among academics surveyed is that Marketing does not need to reduce its theoretical scope, but bring the findings of its research to the day-to-day issues of our society.
\end{abstract}

Keywords: Marketing Theory. Marketing Scope. Marketing Practice.

\section{¿REDUCCIÓN DEL ÁMBITO O AMPLIACIÓN DE LA PRÁCTICA? LAS PERSPECTIVAS DEL MARKETING EN LA VISION DE SUS ACADÉMICOS}

\section{RESUMÉN}

Este artículo tiene como objetivo explorar la visión de académicos del área de Marketing sobre el ámbito conceptual del Marketing. A través de una investigación exploratoria, se realizaron entrevistas semiestructuradas con profesores de la disciplina. Teniendo como objetivo analizar la visión de los mismos sobre cuestiones que aún hoy permean el debate académico del área: el ámbito del Marketing - y la necesidad o no de su revisión, sus límites de actuación, la dicotomía entre teoría y práctica y, sobre todo, la cuestión sobre la cientificidad o no de la disciplina. Por la visión de sus académicos, el artículo busca ampliar la discusión sobre cómo fortalecer la disciplina de Marketing, generando conocimientos que posibiliten avances para su propio marco teórico. En general, fue 
posible observar que la visión predominante entre los académicos investigados es que el Marketing no necesita reducir su ámbito teórico, sino aproximar los hallazgos de sus investigaciones a la práctica y a las cuestiones reales del día a día de la sociedad.

Palabras-clave: Teoría de Marketing. Ámbito de Marketing. Práctica de Marketing

\section{INTRODUÇÃo}

A necessidade de clarificar os fenômenos que envolvem o marketing, bem como sua efetiva contribuição às práticas empresariais aparece nas discussões sobre o escopo da disciplina. Sheth e Sisodia (2006) defendem que o marketing está perdendo eficiência. Buscar consenso acerca das funções de marketing, além de uma aproximação da teoria e prática poderia auxiliar a solucionar o problema identificado pelos autores (LILIEN, 2011).

Desde sua fundação, o conceito de marketing passou por diversas mudanças (BARTELS, 1974). Essas mudanças ainda ocorrem por ser um campo em amadurecimento, que ainda constrói sua teoria e define seus limites de atuação (SILVEIRA; ESTEVES; ROSSI, 2013). Neste sentido, a efetiva cientificidade do marketing ainda hoje precisa ser debatida, de acordo com Lima, Kraemer e Rossi (2014).

As discussões sobre as modificações na compreensão sobre o que é marketing podem emergir de diversas fontes. Uma das possibilidades é partir da relação academia e mercado. Araújo e Kjellberg (2010) afirmam que, durante as décadas de 1960 e 1970, as tentativas de ampliar o conceito de marketing alteraram o seu foco, afastando-o do mercado. Kotler e Levy (1969ab) propuseram que o escopo do marketing deveria ser ampliado para além das trocas comerciais, focando-se também em transações não comerciais. No entanto, Luck (1969) contesta essa visão ao afirmar que a ampliação é prejudicial, e que o marketing perderia sua identidade. Bartels (1974) alerta que uma desvantagem da ampliação do escopo seria a perda da busca por fenômenos relevantes.

Já Hunt (1976) acredita que o escopo do marketing está inserido em três categorias dicotômicas: positivo e normativo; lucrativo e não lucrativo; micro e macro. Kotler e Zaltman (1974), por sua vez, propõem o marketing social, focando os esforços da disciplina no planejamento para mudanças de interesses sociais.

Para Rossi, Bortoli e Castilhos (2014) o conceito de marketing foi mais expandido do que Kotler e Levy (1969ab) entendiam. Esses autores concordam que essa ampliação trouxe elementos fundamentais para a consolidação do campo, mas questionam, entretanto, 
a relevância acadêmica do marketing.

De fato, Silveira, Esteves e Rossi (2013) apontam que pesquisadores de outras áreas possuem uma visão limitada acerca do marketing, pois o mesmo é visto apenas como instrumental e gerencial. A partir de uma análise das citações em artigos científicos, Barcelos e Rossi (2015) identificaram que a contribuição do marketing para outras ciências sociais é muito baixa.

Historicamente, o marketing tem sido uma disciplina extremamente aberta, buscando empréstimos, muitas vezes indiscriminadamente, de métodos, teorias e conceitos de outras áreas disciplinares (HUNT, 2002). Para Araújo e Kjellberg (2010), algumas ações parecem ter reduzido, ao invés de ampliado o escopo da disciplina de Marketing. Além disso, para os autores, o marketing rompeu com a sua origem em mercados e tornou-se "portátil" para a sociedade, como um conjunto de ferramentas e técnicas.

Para Silveira, Esteves e Rossi (2013), o campo deve escolher entre duas trilhas a seguir: consolidar seu atual escopo, estruturando sua definição ou reduzir o escopo e assumir a ênfase na troca econômica e de consumo. Dessa forma, o objetivo geral deste trabalho é identificar sugestões que elucidem os caminhos para que o escopo de marketing fique mais robusto e auxilie, assim, na consolidação do marketing como disciplina científica. Tais sugestões serão embasadas nas percepções dos acadêmicos brasileiros de marketing com relação ao escopo atual da área. Especificamente, os objetivos são avaliar as percepções sobre o conceito de marketing, analisar o entendimento sobre o qual deve ser o escopo da disciplina e verificar qual deveria ser o conceito de marketing, baseando-se no trabalho de Silveira, Esteves e Rossi (2013).

\section{FUNDAMENTAÇÃO TEÓRICA}

Este trabalho foi construído a partir de dois temas relacionados ao debate sobre a ciência do marketing. Dessa forma, esta seção apresenta uma revisão da literatura existente sobre a definição e o escopo de marketing, bem como seu status científico.

\subsection{A DEFINIÇÃO E O ESCOPO DE MARKETING}

Silveira, Esteves e Rossi (2013) desenvolveram uma pesquisa exploratória, com pesquisadores de áreas relacionadas a Marketing, buscando analisar a utilização e interesse pelos conceitos teóricos de Marketing por outras disciplinas. Como resultado, encontraram 
que as outras áreas de conhecimento detêm uma visão limitada sobre a atuação do marketing e um baixo interesse com relação à disciplina. Ademais, os autores identificaram que um consenso sobre o status científico da área é inexistente. Diante disso, destacaram a importância de estimular a discussão sobre uma possível revisão de escopo, que poderia aprofundar o conhecimento sobre Marketing Social, aproximando mais da Economia e explicando o Comportamento do Consumidor.

A necessidade de revisão, exposta a priori, foi destacada por diversos autores, na medida em que, durante os últimos 25 anos, o marketing, como fenômeno, tem mudado. Seguindo esta trajetória, novos campos de marketing, como o marketing de serviços, marketing de relacionamento e marketing baseado em rede business-to-business emergem, ao lado do marketing de produtos orientados ao consumidor (GRÖNROOS, 2006).

$\mathrm{Na}$ base deste trabalho está a definição de marketing da Associação Americana de Marketing (AMA) ${ }^{6}$. A última revisão disponível do conceito de marketing é de 2013: "Marketing é a atividade, conjunto de instituições e processos para criação, comunicação, entrega e troca de ofertas que tenham valor para os consumidores, clientes, parceiros e a sociedade em geral" (AMA, 2013).

\subsection{CIENTIFICIDADE DO MARKETING}

Sheth, Gardner e Garrett (1988) apontam exemplos de autores da área de marketing que divergem sobre a cientificidade da disciplina (arte ou ciência). Como Silveira, Esteves e Rossi (2013) os quais acreditam que essa questão ainda permanece insolúvel.

Hunt $(1976$; 1991) afirma que o marketing pode ser chamado de ciência, considerando a dimensão positiva, proposta por ele. Para o autor, avaliar o marketing apenas na perspectiva normativa tiraria o status científico de qualquer disciplina, pois a ciência pressupõe explicação, predição e entendimento do fenômeno, não podendo ser exclusivamente avaliativa. E ainda afirma que a perspectiva normativa tenta prescrever o que deve ser feito pelas pessoas e organizações.

Yadav (2010) identificou um declínio no número de artigos teóricos em marketing, o que irá gerar um enfraquecimento no papel teórico da disciplina. No Brasil, também se observa um baixo número de artigos conceituais (SAMPAIO, PERIN, LUCE et al. 2012). Silveira, Esteves e Rossi (2013) identificam que pesquisadores de áreas afins do marketing divergem sobre o status científico da disciplina, entretanto, concordam que se trata de uma

${ }^{6}$ Disponível em: https://www.ama.org/AboutAMA/Pages/Definition-of-Marketing.aspx. 
área de conhecimento aplicado, utilizando teoria de outras áreas e produzindo pouco conhecimento.

Barcelos e Rossi (2015) questionam se o predomínio de trabalhos empíricos sobre teóricos, identificado por Yadav (2010), está prejudicando o status científico do marketing. Vieira (2013) destaca a resistência dos pesquisadores brasileiros de marketing com relação às técnicas qualitativas, enquanto Barcelos e Rossi (2015) identificam que artigos de metodologia em marketing apresentam alto nível de contribuição para outras áreas, sobretudo, a administração. Por sua vez, Lima, Kraemer e Rossi (2014) acreditam que a identificação do maior número de artigos sobre metodologia, e não epistemologia demonstra uma preocupação cada vez maior com as pesquisas empíricas em marketing. Bass (1995), baseando-se em Nagel (1961), afirma que a ciência consiste em generalizações empíricas e explicações generalizadas das generalizações empíricas. Hubbard e Lindsay (2002) destacaram que é baixo o número de replicações nos estudos em marketing, mesmo com o acentuado papel que as generalizações empíricas desempenham na ciência (HUNT, 1991; 2002).

\section{MÉTODO}

A opção por uma abordagem exploratória para o desenvolvimento deste trabalho deveu-se ao fato de que o objetivo é investigar aspectos voltados ao entendimento e à interpretação sobre o escopo da disciplina de marketing que, por suas características, não exige uma mensuração, mas sim uma ampliação da compreensão existente. A utilização de uma pesquisa exploratória, de acordo com Malhotra (2006), possibilita a descoberta de novas ideias e percepções, dada sua flexibilidade e versatilidade, muitas vezes o ponto de partida de toda a concepção de pesquisa.

Zikmund (2006) destaca que a não utilização de técnicas estatísticas não significa que as análises qualitativas sejam especulações subjetivas, ou que os pesquisadores não devam ser cuidadosos e sistemáticos. Assim, para melhor organizar a investigação, aproximando-a do maior rigor científico possível, definiu-se pela divisão do trabalho em três etapas, descrita a seguir. Primeiramente, foi realizado um levantamento teórico/bibliográfico, buscando sustentação teórica e ao mesmo tempo insights para a elaboração do roteiro semiestruturado para as entrevistas em profundidade. Sequencialmente, foram coletados os dados, a partir das referidas entrevistas com os docentes da área de marketing. Por último, foi feita a transcrição das entrevistas e a análise 
dos conteúdos das mesmas.

\subsection{COLETA DE DADOS}

Para esta etapa, condução das entrevistas, a qual pode ser considerada a parte central da pesquisa exploratória, foi construído um roteiro semiestruturado (Apêndice A).

\subsection{AMOSTRA E REGISTRO DAS ENTREVISTAS}

Para a montagem da amostra, inicialmente foi feito um levantamento de todos os professores da área de marketing através do site da Associação Nacional de Pós-Graduação e Pesquisa em Administração ANPAD, os quais foram contatados por e-mail solicitando a disponibilidade em responder ao questionário. Além disso, foram utilizadas as relações pessoais dos pesquisadores e realizados contatos diretos com potenciais entrevistados. As entrevistas foram realizadas entre os dias 02 e 08 de agosto de 2016, com professores de marketing de instituições de ensino reconhecidas pelo MEC no Brasil. Todas as entrevistas foram gravadas em mídia digital e posteriormente transcritas. As entrevistas foram realizadas com 15 professores, dos quais 8 via Skype, 5 em encontros presenciais e outras 2 em questionários enviados por e-mail e devolvidos com as respostas. O tempo mínimo foi 12 minutos e o máximo de 45 minutos. Após a realização das 15 entrevistas, fícou perceptível que as informações dos respondentes começaram a ter similaridades e repetições. Atingiu-se, neste ponto, a chamada redundância de respostas, estágio em que se definiu pelo encerramento da coleta de dados. A Tabela 1 apresenta o perfil da amostra com relação ao foco acadêmico dos entrevistados.

Tabela 1 - Disciplinas ministradas pelos entrevistados

\begin{tabular}{cccc}
\hline Disciplinas & Professores & Disciplinas & Professores \\
\hline Comportamento do & 3 & Consumo, Marketing e & 1 \\
Consumidor & 5 & sociedade & 2 \\
Marketing de Serviços & 1 & Introdução ao Marketing & 1 \\
Marketing do Varejo & 1 & Métodos de Pesquisa & 1 \\
Gestão de Marketing & 3 & Métodos de Estatística & 1 \\
Marketing Estratégico & 1 & Aplicados à Administração & 1 \\
Temas Emergentes em & 3 & Fundamentos de Marketing & 1 \\
Marketing & 1 & Técnicas de levantamento e & 1 \\
Teoria em Marketing & análise de dados & 1 \\
Métodos qualitativos e & 1 & Planejamento de marketing & 1 \\
aprendizagem organizacional & Práticas de marketing e & & \\
mercados & &
\end{tabular}


Conforme Flick (2004), a interpretação dos dados é a essência da pesquisa qualitativa. Neste trabalho, a análise e interpretação dos dados foram fundamentadas na análise de conteúdo, de acordo com os postulados de Bardin (1977) e Minayo (2012). De acordo com Bardin (1977), a análise de conteúdo é utilizada no sentido de realizar categorizações a partir das entrevistas.

Segundo Bardin (1979), é possível realizar categorizações a partir de vários critérios, tais como: semânticos (categorias temáticas), sintáticos (categorias referentes a verbos, adjetivos, advérbios, etc), léxicos (ordenamento interno das orações), expressivos (categorias que se referem a problemas de linguagem, por exemplo), sendo que a escolha para este trabalho recaiu sobre a categorização temática. Assim, para este estudo a categorização foi feita objetivamente com base nas perguntas do questionário, abrigando em cada um dos itens os comentários que, na visão dos autores, ilustram com maior precisão os aspectos investigados.

\section{RESULTADOS}

\subsection{A DEFINIÇÃO DE MARKETING: PONTO DE PARTIDA}

Há diversas discussões sobre uma definição ideal para o marketing. Para Grönroos (2006), ela deveria ser um pouco abstrata, mas sem perder o seu poder como um guia para ensinar e praticar o marketing. Por exemplo, nos últimos 50 anos têm sido geralmente aceito que o marketing está na relação entre empresas e seus clientes atuais e potenciais (GRÖNROOS, 2006).

Para efeitos deste estudo, a definição da AMA (2013) foi utilizada introdutoriamente à conversa com os acadêmicos entrevistados. Assim, antes de ser abordada a questão do escopo, foi levantada a discussão sobre a cientificidade da disciplina, apresentada a definição e solicitada a opinião dos entrevistados sobre a mesma.

Não houve um consenso entre os respondentes quanto à questão se o Marketing consegue abranger tudo o que se propõe em sua definição, se haveria algo faltando ou sobrando. No entanto, é nodal observar que nenhum acadêmico falou em diminuir algo na definição; acrescentariam, substituiriam ou manteriam, mas não a deixariam mais enxuta. 
Almejando compreender as respostas, propusemos uma classificação na análise do conteúdo. Primeiramente, estão dispostas as citações dos que acreditam que seja preciso acrescentar outros aspectos à definição da AMA (2013). Dentre os destaques estão a ausência da tecnologia, restrição das trocas comerciais, tipo de organizações a que se destina, resgate das necessidades e desejos:

A questão da tecnologia provavelmente terá que receber maior atenção, ou pelo menos mais destaque que tinha nas definições anteriores. (Respondente 3)

A troca de valores entre duas pessoas na família seria marketing? Isso não está explícito nisso daí. A questão de trocas de valores eu entendo que é muito mais do ponto de vista de marketing, entre instituições e consumidores, não é? [...] O segundo aspecto que eu acho que talvez ainda não está suficientemente claro é quanto também ao papel do marketing em termos de indução de mudança de valores. (Respondente 5)

Vamos falar o que a gente vê em sala de aula quando se fala em conceito, as pessoas ainda não têm clareza que tu trabalhas isso no nível de qualquer tipo de organização. Então talvez teria que estar um pouco mais forte a palavra organizacional nesses conceitos. (Respondente 11)

Sinto falta de uma questão que é a organização, de uma organização, pública ou privada, para a sociedade [...] E também sinto falta um pouquinho da questão de resgatar necessidades, desejos, o olhar para o consumidor. A entrega, a oferta tem que ser adequada. Ali tem o valor para os consumidores e clientes, mas que seja bem direcionada para este público-alvo. (Respondente 13)

Em segundo lugar, estão as falas que representam as substituições desejadas:

Substituiria criação por co-criação. (Respondente 1)

No concordo com a definição de que o marketing seja 'um conjunto de instituições'. Se é uma atividade, um processo, não é um conjunto de instituições. Prefiro a ideia de que seja uma filosofia de negócio. (Respondente 7)

Da mesma forma, alguns se posicionaram a favor da definição atual, não considerando necessária qualquer modificação: 
Ele é amplo, abrangente, tenta ser politicamente correto porque não deixa de fora ninguém (ou tentar não deixar ninguém de fora) e trabalha com a ideia que surgiu no final dos anos 90, que se tornou mais top no final dos anos 2000, que é a ideia da criação de valor. (Respondente 4)

É um conceito ampliado o recente deles, eu acho que é um conceito mais completo e atualizado, eu gosto do conceito. (Respondente 9) É um conceito bem abrangente, bem interessante, que cumpre o papel. (Respondente 14)

É claro e completo, não vejo nenhum problema. (Respondente 15)

Por último, seguem aqueles que preferiram apenas discorrer sobre a definição, sem deixar claro o seu posicionamento:

Associa algumas preocupações da sociedade ou da própria academia dentro do próprio conceito, dá um direcionamento importante. (Respondente 2)

Então acho que ele é um conceito que amplia um pouco mais o escopo de marketing e muda um pouco também da atenção também pra uma ideia, no meio do conceito tem a ideia da criação, entrega e oferta de valor ela dá atenção um pouco para essa lógica de valor do cliente e também está dentro da discussão de valor. (Respondente 6)

Ainda enfocando essa questão da troca, não deixa de ser questionável também, porque já há mais tempo isso havia sido revisto, trazendo mais a questão do relacionamento do que da troca em si. Esse conceito é claro que são importantes, ajudam a compreensão melhor, mas são mutáveis. (Respondente 8)

Uma definição que abrange diversas atividades e instituições, sendo ampla para diversos negócios e segmentos. (Respondente 10)

Essa última definição vai exatamente ao encontro desses propósitos, ou seja, ela delimita qual escopo efetivo o marketing deva atuar. Ela obviamente, mantém a lógica que tu tens um escopo que vai além da relação específica com clientes apenas. (Respondente 12) 


\subsection{PERSPECTIVAS DE FUTURO}

Quando a interrogação passa ser o futuro do marketing e como este pode ganhar relevância, se fortalecer e se aproximar da ideia de ciência, as opiniões orbitam entre a concordância com a imagem ruim e uma tentativa de racionalização entre os acadêmicos: "reconheço a imagem desgastada, mas desejo que a disciplina se posicione mais claramente como ferramenta de melhoria social" ou "quando eu trabalho com meus alunos o marketing social, quando falo a questão da responsabilidade social na distribuição de um produto, de um serviço, eu acho que torna mais relevante e foge daquela concepção só capitalista". Barcelos e Rossi (2013) convergem nesta direção, ao demonstrar "a baixa contribuição do conjunto da produção em marketing para as outras ciências sociais, exceto para a administração" (p.214).

Entre os precursores nesta visão, Kotler e Levy (1969a) sugeriram que o conceito de Marketing deveria ser ampliado para incluir, por exemplo, organizações sem fins lucrativos, pois, segundo estes mesmos autores (1969b), se a definição não fosse expandida, o Marketing estaria restrito ao seu crescimento nas organizações. Kotler e Zaltman (1971), por sua vez, salientaram a importância da inclusão da dimensão social no escopo da disciplina.

Ainda no mesmo sentido, outros comentários adotam esse viés, ao entenderem a necessidade da aproximação com a prática e com as demandas sociais como caminho para a consolidação do marketing como ciência:

Dentro da dimensão filosófica eu acho que é caminhar exatamente nesse sentido, no sentido mais abrangente de stakeholders, no sentindo de uma preocupação de um jogo ganha-ganha. Uma preocupação mais de marketing social como conceito e não campo de aplicação apenas, não é? (Respondente 5)

O usuário da ciência do marketing tem que começar a usar mais ciência nas grandes corporações nas quais a gente tem contato e nas grandes multinacionais [...] o uso da ciência em marketing é pífio se você olhar a tecnologia de marketing, ou seja, a tecnologia que a ciência do marketing criou nos últimos 30 anos, o uso, os caras estão usando tecnologias de 40 anos atrás, da década de 60, 70, 80 há tecnologias que teoricamente estariam ultrapassadas. Ou 
seja, esse gap, essa ponte entre ciência e prática ela precisa acontecer tanto no pesquisador quanto no prático na minha visão para se consolidar mais propriamente como uma ciência. (Respondente 6)

Quando eu levo esse conceito mais amplo, essa concepção mais ampla de marketing, quando eu trabalho com marketing social, quando eu falo a questão da responsabilidade social na distribuição de um produto, de um serviço, eu acho que torna mais relevante e foge daquela concepção só capitalista. (Respondente 13)

\subsection{CAMINHOS PARA O MARKETING}

A natureza e a amplitude do escopo de marketing parecem não ser ponto central de preocupação dos acadêmicos de marketing entrevistados. Diante do questionamento se o marketing deveria se consolidar com o escopo atual, enfatizando a dimensão social e estabelecer um corpo teórico mais robusto, baseado na reflexão crítica sobre seus efeitos na sociedade, os professores da área se posicionaram de maneiras convergentes, conforme destaques abaixo:

Acho que sim, se for pensar no escopo ou no objetivo do marketing, nós vamos trabalhar o marketing como ciência, eu vou tentar identificar, definir, entender fenômenos mercadológicos, mas que o objetivo desse entendimento seja beneficiar, ou tornar, as relações comerciais mais funcionais, gerando riqueza e bem-estar, em última análise. (Respondente 1)

Sim. Desde que tenha claro que o seu objetivo é oferecer trocas satisfatórias para o seu público alvo trazendo lucro para a empresa. Sei que este é o conceito mais clássico (antigo) de marketing, mas é a base desta ciência. Empresa que não gera lucro vai à falência. (Respondente 7)

Sim, isso eu acredito muito, eu acredito muito que esse aspecto precisa ser melhor abordado, essa relação com a sociedade, o impacto das práticas de marketing na sociedade, eu acho que, 
essa é uma temática de fundamental importância [...].

(Respondente 8)

Da mesma forma, Hackley (2009) aborda a questão ao colocar que há, ainda, pesquisadores que defendem que o Marketing só poderá alcançar o progresso científico se estiver engajado em questões sociais ou, então, ficará reduzido à resolução de problemas técnicos.

\subsection{APENAS TROCAS?}

Conceito central desde a origem da disciplina de marketing as trocas voltam ao palco das discussões quando se busca estudar, redefinir ou delimitar o escopo da disciplina. Assim, a questão levantada aos pesquisadores foi se o escopo de marketing deveria se restringir apenas ao estudo de trocas comerciais ou também a outros tipos de trocas, ou até mesmo se deveria abranger outros aspectos além das trocas.

Neste sentido, um dos entrevistados diz objetivamente: "É, trocas comerciais, mesmo que seja envolvendo instituições sem fins lucrativos. Mais do que isso não é marketing", no que é seguido por outros, com maior ou menor ênfase e pequenas variações no enfoque:

Só trocas comerciais, não. Eu acho que pensar em termos de troca é uma questão central da nossa área, como tal deve é uma preocupação que deve ter, mas só troca eu acho que não. Eu acho que existem fenômenos que pelo entendimento do próprio fenômeno a área ganharia. (Respondente 2)

Assim, claro que deveria abranger, além de trocas, essa definição do Kotler, essa definição seminal da ideia de troca, e depois foi trabalhada por Bagozzi, eu acho que hoje é... assim, se ampliou demais e a noção de troca que se tem hoje é uma noção do ponto de vista social, não é mais apenas a troca de produtos, ou produtos por moeda, ou me dê dinheiro e eu te dou produto ou serviço, ela, eu acho que marketing ele é mais amplo que isso, quer dizer, isso está no centro, mas a própria definição da AMA [...]. (Respondente 4)

Eu acho que esse aí já é um conceito antigo, acho que o marketing já evoluiu disso, da questão de troca. Troca é uma condição 
necessária, mas não suficiente. Posteriormente, já evoluiu disso para uma questão de relacionamento de longo prazo, para uma questão de inúmeros stakeholders, não mais apenas dentro de uma visão estrita de consumo, de consumo de bens e serviços, mas uma visão mais ampla de valores que são transacionados $e$ relacionados entre públicos. E o que coloco nesse sentido é que essa questão de relacionamento de longo prazo poderia estar mais calcada mais dentro da visão social, da visão societária, dos diferentes públicos envolvidos, da sociedade como um todo, para depois, digamos, assim dentro disso dai fazer os ajustes de trocas ou de relacionamentos no plano do consumidor mais individual em si. (Respondente 5)

Na mesma dimensão estão Araújo e Kjellberg (2010), os quais afirmam que o conceito genérico de Marketing indica que todas as formas de trocas devem ser cobertas, não somente aquelas que ocorrem no mercado. Para Barcelos e Rossi (2013), existe ainda a opção de se esforçar na consolidação de teorias próprias do Marketing, buscando explicar, por exemplo, a troca (econômica) entre organizações e sociedade, isto é, tomando para si o mercado como objeto de estudo tal qual faz a Economia, deixando assim de entender o Marketing como uma função interna às empresas para vislumbrá-lo como um fenômeno maior do que elas e do âmbito da sociedade.

\subsection{CIENTIFICIDADE DO MARKETING}

Conforme evidenciado no referencial teórico, não existe um discurso uníssono sobre a cientificidade do marketing entre os autores da área e áreas afins (SILVEIRA, ESTEVES e ROSSI, 2013). Esse debate fica evidente através das entrevistas realizadas: Nove respondentes acreditam que o marketing é uma ciência, três afirmam que não e três mantiveram uma posição neutra.

Entre àqueles que adotam a perspectiva de ciência, identificam-se elementos os quais reforçam como a existência de fenômenos específicos das relações de mercado, a capacidade de generalização do marketing e a questão de interdisciplinaridade e multidisciplinaridade. 
Pela amplitude, pela multidisciplinaridade e interdisciplinaridade que o marketing chegou no momento eu vejo que é uma ciência [...]. (Respondente 11)

Na minha opinião é, porque eu acho que a gente já tem um conjunto de pensamento, de conhecimento, de resultados que pode ser replicado que é bastante geral para se aplicar diversas situações, na minha concepção é ciência sim. (Respondente 9)

“á controvérsias, sempre houve, sempre haverá, mas é, porque já tem um corpo teórico desenvolvido, existem fenômenos que são específicos das relações de mercado. É isso que o marketing se ocupa em tratar. Então, no momento em que tens este corpo teórico que te ajuda a entender esses fenômenos e busca, inclusive em outras disciplinas, as explicações, seja na psicologia, na economia, na antropologia, enfim. Acho que isso caracteriza o marketing como ciência, sim! (Respondente 1)

O que se observa com as entrevistas, através de alguns trechos abaixo destacados, é uma justificativa do status científico do marketing baseada em questões metodológicas. Conforme se demonstrou no referencial teórico, existe uma queda recente em artigos puramente teóricos (YADAV, 2010), e artigos de cunho metodológico estão dentre os mais citados por outras áreas (BARCELOS e ROSSI, 2015).

Acho que o aspecto que deixa mais evidente a cientificidade é o aspecto do método quantitativo, se aproximando das ciências exatas. (Respondente 3)

A gente tem muitos recursos para explicar, empiricamente, tentar extrair conclusões válidas, generalizáveis nesse sentido para promover mudanças no patamar teórico e ir fortalecendo cada vez mais a teoria com um corpo unificado consolidado. (Respondente 5)

Acho que na verdade que quando a gente entende a ciência da administração, as áreas da administração, o marketing acaba se destacando nessa preocupação com os métodos de pesquisa, as técnicas, os tratamentos que são dados, nesse sentido é uma contribuição relevante para áreas de fronteira, então dentro dessa 
perspectiva o marketing sim, tem consistência para ser visto como ciência [...]. (Respondente 8)

A começar pela própria metodologia de pesquisa. A gente busca metodologias robustas o tempo todo. Hoje inclusive, se fizermos uma análise uma pouco mais fria, a gente tem uma rigidez metodológica tão forte, tão rígida, que muitas vezes desvirtua o objeto de pesquisa, entendeu? [...] Mas é natural, talvez por ser ainda uma ciência em processo de autoafirmação, agarrar essa questão metodológica e dizer assim: Isso eu me garanto. (Respondente 14)

No entanto, para alguns respondentes o marketing não pode ser visto como uma ciência, em parte pela complexidade dos fenômenos estudados na disciplina.

Do ponto de vista positivista, eu acho que a gente vem se afastando gradualmente da condição de ciência [...] Tanto é que obviamente tu acaba, para conseguir compreender certos fenômenos, abrindo mão de uma lógica de ciência tradicional, baseada, enfim, sobretudo em uma ideia de quantificação, generalização, mensuração, etc. [...] então ciência de um enfoque mais, como costumo falar, clássico que é o positivista da coisa, pra mim a gente está se distanciando, porque a gente cada vez mais está se deparando com fenômenos que não conseguem ser trabalhados, digamos daquela forma, podem ser interpretados, compreendidos etc. (Respondente 12)

Não, ainda não. Mas ele pode se tornar, se a gente conseguir fundamentar. Exatamente, sabe, tipo a fórmula de Bhaskara do marketing. Precisa ter esse histórico, esses pressupostos. A gente precisa saber que sempre que for assim vai acontecer de tal maneira, que a gente consiga ter formas de identificar que dê resultados. Formas mais precisas também, porque na verdade hoje a gente sabe que uma mesma estratégia pode ter resultados totalmente diferentes em contextos diferentes, com pessoas diferentes. (Respondente 15)

A gente sempre aprendeu que marketing faz parte da administração, e a administração por si também não é uma ciência, então estaria dentro das ciências sociais aplicadas. 
Quebrar essa noção, essa concepção é um pouco complicada. Eu acho que ela não é uma ciência, não. Acho que se vale de outras ciências, como a psicologia, as ciências sociais. Seria uma disciplina, um ramo multidisciplinar, eu diria. (Respondente 13)

É possível constatar que grande parte dos respondentes acredita que a disciplina de marketing pode ser analisada tanto no aspecto acadêmico, quanto no profissional. Embora tenha respondentes que a analisam apenas como profissional.

Ela pode ser as duas coisas. Aí entra de novo nos textos mais antigos que falavam do marketing como sendo normativo ou positivo. Eu acho que tem espaço para as duas coisas. (Respondente 1)

Ciência profissional. (Respondente 7)

Apesar dessa percepção de ciência profissional, uma preocupação recorrente entre os entrevistados foi a pouca aplicabilidade gerencial da pesquisa em marketing, ou seja, o conhecimento produzido na acadêmica fica restrito aos acadêmicos, pouco é aplicado no contexto empresarial pelos praticantes, havendo falta de comunicação entre esses grupos. Alguns entrevistados entendem que essa falta de comunicação possa vir atrapalhar o status científico do marketing. Kohli (2011), ao introduzir uma edição especial dos 75 anos do Journal of Marketing (SAMPAIO, PERIN, LUCE et al. 2012), afirma que: "a geração, disseminação e uso pelos praticantes do conhecimento acadêmico é um Santo Graal para muitos" (KOHLI, 2011, p. 128).

Com certeza agora que tem um maior número de pesquisadores, de novo, tem que dar um pouco mais de sentido na questão de aplicabilidade desta ciência, dentro da academia a fora, principalmente fora da academia e junto a outras áreas, ai é um caminho de dois sentidos, não é? (Respondente 11)

Isso é uma das questões da ciência, é disseminar conhecimento para ser legitima. $O$ quanto nós conseguimos disseminar esse conhecimento para chegar nas pessoas, e chegar até as pessoas para a tomada de decisão. (Respondente 3)

O marketing pode ser visto como ciência a partir do momento que ele gera conhecimento e depois esse conhecimento pode ser aplicado o pessoal do mercado para suas atividades, para o seu dia a dia, 
para que desenvolva essas trocas, essas relações de forma mais apropriada, então em algum sentido sim, podem ser entendidas como ciência. (Respondente 8)

Eu falo não só em nível de Brasil, a nível mundial, a nível global em marketing a gente ainda se comunica de uma forma pouco cientifica, e eu acho que por nós estarmos dentro de uma área que é uma área social aplicada como a administração, a gente ainda sofre de um trade-off, ou seja, ou eu vou para a ciência ou eu vou para a aplicação [...] eu, por exemplo, reviso para vários periódicos, tanto nacionais quanto internacionais e a média dos artigos que eu tenho pego nos últimos tempos é assim é muito claro isso o autor tenta dar uma visão de ciência e tenta das uma visão de aplicação, e ele não consegue fazer nem um e nem outro [...] e pra que a ciência em marketing, ela se estabeleça, essa junção de ciência e prática ela tem que acontecer e os práticos, ou seja, os usuários da ciência do marketing têm que começar a usar mais ciência nas grandes corporações. (Respondente 6)

Muito do que está ali (na definição da AMA) são desafios que estão postos. Então isso vem da própria aplicabilidade daquilo que eu pesquiso, então, se o conceito, melhor essa busca incessante por ser ciência, acabe engessando daquilo que é, e não é difícil encontrar quem pense assim, da aplicabilidade, de modelos maravilhosos que sempre fecham com índices de ajustamento perfeito, mas que vai trabalhar isso dentro das organizações para gerar resultados e isso não funciona. No momento a questão é: quem é o senhor do marketing em si, né? A ciência e o status quo que ele gera, e o status que ela gera para alguns é interessante? Ou a relevância efetiva de solução, na medida do possível, num prazo relativamente curto, não digo nem de solução, de entendimento de fenômenos que permitam, enfim, às organizações, os atores diretamente ligados a ela e a sociedade como um todo terem um resultado mais satisfatório, enfim, se desenvolvam de maneira positiva? (Respondente 12)

É possível observar, portanto, que há uma preocupação dos acadêmicos com a 
aplicabilidade prática da produção acadêmica, pois a consideram insuficiente. Nota-se que a aproximação das pesquisas acadêmicas com as práticas gerenciais deveria permear as agendas dos debates epistemológicos na área de marketing. De acordo com as entrevistas realizadas nesta pesquisa, essa é uma prioridade que se sobrepõe a um esforço de delimitação, de discussão sobre status científico (versus teórico) e de ampliação (versus redução) do escopo.

\section{CONCLUSÃO}

A partir das declarações dos entrevistados e do exposto no referencial teórico, acredita-se que seja necessário maior esforço dos pesquisadores em marketing em aproximar a academia das práticas de mercado. Assim, é possível intensificar a troca de conhecimento e aplicabilidade dos resultados obtidos pelos acadêmicos. Ainda, parece ser necessário construir uma filosofia entre os pesquisadores sobre a relevância das replicações para o processo científico.

Entende-se que esforços devam ser empreendidos na ampliação de artigos conceituais que busquem debater e delimitar, a partir de todo conhecimento empírico já construído, quais elementos discutidos em marketing efetivamente relacionam-se com o fenômeno e como eles irão auxiliar as práticas organizacionais.

Este trabalho deriva da premissa de Silveira, Esteves e Rossi (2013) que sugerem dois caminhos para a academia de marketing: A permanência no escopo atual, com ênfase a dimensão social, ou uma restrição às trocas e aprofundamento da teoria sobre o comportamento do consumidor. Com base nos resultados aqui obtidos, os acadêmicos brasileiros se posicionam em uma linha que entende o papel do estudo das trocas e do relacionamento, mas compreendendo o fenômeno do marketing mais amplo que isso.

Em suma, parece que o essencial, no ponto de vista dos acadêmicos entrevistados, é delimitar as trocas comerciais como aspecto central do marketing, colocando o bem-estar social também como aspecto fundamental da prática do mesmo, tanto em organizações de caráter público quanto privado. Ou seja, as consequências das atividades de marketing alcançam a sociedade em geral.

Ademais, para os pesquisadores a dimensão social não deve ser deixada de lado, uma vez que ela pode auxiliar no reconhecimento de outras áreas do conhecimento sobre o papel do marketing. Embora nenhum respondente tenha se posicionado claramente sobre como reduzir o escopo, vários comentaram sobre como a disciplina deveria ficar para ser 
mais forte e mais relevante.

Para futuros estudos, é sugerido que desenvolvam uma escala - com base nos resultados de Silveira, Esteves e Rossi (2013) e do presente estudo - aplicando-a para acadêmicos de marketing e áreas afins, buscando comparar as percepções de ambos os grupos sobre os tópicos debatidos nesses artigos. É preciso ressaltar que esses estudos estão restritos aos pesquisadores brasileiros, portanto, novas pesquisas deveriam buscar respondentes de outros países.

\section{REFERÊNCIAS}

\section{ALVES-MAZZOTTI, A. J.; GEWANDSZNAJDER F. O método nas Ciências} Naturais e Sociais: pesquisa quantitativa e qualitativa. São Paulo: Pioneira, 1998. AMERICAN MERKETING ASSOCIATION. Definition of Marketing. Disponível em: https:// www.ama.org/AboutAMA/Pages/Definition-of-Marketing.aspx. Acessado em 09 de agosto de 2016.

ARAUJO, L.; KJELLBERG, H. Shaping exchanges, performing markets: the study of marketing practices. In: MACLARAN, P.; SAREN, M.; STERN, B.; TADAJEWSKI, M. (Eds.) Handbook of marketing Theory. Los Angeles: Sage, 2010.

BASS, F. M. Empirical generalizations and marketing science: a personal view. Marketing Science, v. 14, n. 3_supplement, p. G6-G19, 1995.

BARCELOS, R. H.; ROSSI, C. A. V. A contribuição da produção científica em Marketing para as Ciências Sociais. Revista de Administração Contemporânea. v. 19, $2^{\text {a }}$ ed. esp. (ago. 2015), p. 197-220, 2015.

BARDIN, L. Análise de conteúdo. Lisboa: Ed. Persona, 1979.

BARTELS, R. The identity crisis in marketing. The Journal of Marketing, v. 38, n. 4, p. 73-76, 1974.

DE LIMA, M. P.; KRAEMER, F.; ROSSI, C. A. V. A Discussão epistemológica em Marketing 1990-2010. Revista Brasileira de Marketing, v. 13, n. 1, p. 133, 2014.

FLICK, U. Introdução à pesquisa qualitativa. Bookman, 2008.

GRÖNROOS, C. On defining marketing: finding a new roadmap for marketing.

Marketing theory, v. 6, n. 4, p. 395-417, 2006.

HACKLEY, C. Marketing: a critical introduction. Sage, 2009.

HUBBARD, R.; LINDSAY, R. M. How the emphasis on 'original' empirical marketing research impedes knowledge development. Marketing Theory, v. 2, n. 4, p. 381-402, 
2002.

HUNT, S. D. The nature and scope of marketing. Journal of Marketing, v. 40, n. 3, p. 17-28, 1976.

HUNT, S. D. Modern marketing theory: critical issues in the philosophy of marketing science. South-Western Pub, 1991.

HUNT, S. D. Foundations of Marketing Theory: toward a general theory of marketing. Armonk: M. E. Sharpe, 2002.

KOHLI, A. K. Introduction to the Journal of Marketing 75th Anniversary Special Section. Journal of Marketing, v. 75, n. 4, p. 128, 2011.

KOTLER, P.; LEVY, S. J. Broadening the concept of marketing. The Journal of Marketing, v. 33, n. 1, p. 10-15, 1969a.

KOTLER, P.; LEVY, S. J. A new form of marketing myopia: rejoinder to Professor Luck. The Journal of Marketing, v. 33, n. 3, p. 55-57, $1969 \mathrm{~b}$.

KOTLER, P.; ZALTMAN, G. Social marketing: an approach to planned social change. The Journal of Marketing, v. 35, n. 3, p. 3-12, 1971.

LILIEN, G. L. Bridging the academic-practitioner divide in marketing decision models. Journal of Marketing, v. 75, n. 4, p. 196-210, 2011.

LUCK, D. J. Broadening the concept of marketing: too far. The Journal of Marketing, v. 33, n. 3, p. 53-55, 1969.

MALHOTRA, N. K. Pesquisa de marketing: uma orientação aplicada. Porto Alegre, $4^{\mathrm{a}}$ ed., Bookman, 2006.

MINAYO, M.C.S. (Org.) Pesquisa Social: Teoria, método e crriatividade. 32a Edição. Petrópolis/ RJ. Editora Vozes, 2012.

ROSSI, C. A. V.; BORTOLI, V.; CASTILhOS, R. B. Análise bibliométrica da contribuição de marketing para outras ciências. Revista de Ciências da Administração, p. 29-44, 2014.

SAMPAIO, C. H.et al. Pesquisa científica da área de Marketing no Brasil: Uma revisão da primeira década do século 21. Revista de Administração Contemporânea, v. 16, n. 3, p. 459-478, 2012.

SHETH, J. N.; GARDNER, D. M.; GARRETT, D. E. Marketing theory: evolution and evaluation. John Wiley \& Sons Inc, 1988.

SHETH, J. N.; SISODIA, R. S. Does marketing need reform?: Fresh perspectives on the future. M.E. Sharpe, 2006.

SILVEIRA, C. S.; ESTEVES, P. S.; ROSSI, C. A. V. O que os outros pensam sobre 
marketing? A contribuição da disciplina para as ciências sociais. Revista Brasileira de Marketing, v. 12, n. 2, p. 49-69, 2013.

VIEIRA, F. G. D. Perspectivas e limites da pesquisa qualitativa na produção de conhecimento em Marketing. Revista de Negócios, v. 18, n. 1-15, p. 10-24, 2013.

YADAV, M. S. The decline of conceptual articles and implications for knowledge development. Journal of Marketing, v. 74, n. 1, p. 1-19, 2010.

ZIKMUND, W.G. Princípios da Pesquisa de Marketing. 2.ed. São Paulo: Pioneira Thomson Learning, 2006.

\section{APÊNDICE A - ROTEIRO SEMIESTRUTURADO DE ENTREVISTA}

Nome

Instituição de ensino onde leciona / Nome da

disciplina Tempo de docência

1) Qual a sua opinião sobre o mais recente conceito de marketing definido pela Associação Americana de Marketing (AMA, 2013)?

"Marketing é a atividade, conjunto de instituições e processos para criação, comunicação, entrega e troca de ofertas que tenham valor para os consumidores, clientes, parceiros e a sociedade em geral. "(AMA, 2013)

2) Você acha que o Marketing consegue abranger tudo o que se propõe em sua definição? O que está faltando/sobrando?

3) Como ela pode se tornar uma ciência/disciplina mais forte? Quais aspectos deve focar?

4) O marketing deveria se consolidar com o escopo atual, enfatizando a dimensão social e estabelecer um corpo teórico mais robusto baseado na reflexão crítica sobre seus efeitos na sociedade?

5) O escopo de marketing deveria se restringir apenas ao estudo de trocas comerciais? Outros tipos de trocas?

6) O que mais (e se) deveria abranger além das trocas? O marketing é uma ciência?

7) Em caso afirmativo: por que você acha isso? Quais aspectos deixam essa cientificidade mais saliente?

8) Você acha que o Marketing é uma ciência profissional (assim como a Medicina) ou acadêmica? Em caso negativo: o que está faltando/sobrando para que se torne uma ciência? 